Ann N Y Acad Sci. 2016 January ; 1364(1): 25-31. doi:10.1111/nyas.12968.

\title{
Wnt/ $\beta$-catenin signaling plays a key role in the development of spondyloarthritis
}

\author{
Wanqing Xie ${ }^{1,2}$, Lijiang Zhou ${ }^{1,2}$, Shan $\mathrm{Li}^{1}$, Tianqian Hui ${ }^{1}$, and Di Chen ${ }^{1,{ }^{*}}$ \\ ${ }^{1}$ Department of Biochemistry, Rush University Medical Center, Chicago, IL. \\ ${ }^{2}$ Liaoning University of Traditional Chinese Medicine, Shenyang, China
}

\begin{abstract}
Spondyloarthritis ( $\mathrm{SpA})$ is a group of diseases consisting of psoriatic arthritis (PsA), reactive arthritis, arthritis related to inflammatory bowel disease (a subgroup of juvenile idiopathic arthritis), and ankylosing spondylitis (the prototype of $\mathrm{SpA}$ ). Axial bone formation and the combination of concurrent erosion and new bone formation are specific characteristics of SpA disease. The use of anti-proinflammatory cytokines, such as inhibitors of tumor necrosis factor a (TNF-a), appears to be the greatest advance in the treatment of SpA over the past 20 years. However, TNF-a blockers do not halt new bone formation. Recent clinical observations and animal studies demonstrate that Wnt signaling proteins and natural Wnt inhibitors, such as DKK1 and sclerostin, are likely to play important roles in the process of ankylosis in $\mathrm{SpA}$, and could potentially serve as therapeutic targets for the treatment of SpA.
\end{abstract}

\section{Keywords}

spondyloarthritis; Wnt signaling pathway; DKK1; sclerostin; bone formation

\section{Spondyloarthritis}

In 1974, Moll and colleagues ${ }^{1}$ defined a group of rheumatic diseases as spondyloarthritis (SpA), and separated SpA from other rheumatic diseases based on clinical features and a common genetic predisposition. SpA encompasses axial and peripheral spinal arthritis. ${ }^{2,3}$ However, for clinical purposes, SpA is normally divided into five major subtypes, including ankylosing spondylitis (AS), psoriatic arthritis (PsA), reactive spondylitis (ReSpA), SpA associated with inflammatory bowel disease (IBD), and undifferentiated SpA (uSpA). ${ }^{4}$ The most important clinical features of SpA are inflammatory back pain, asymmetric peripheral oligoarthritis, predominantly of the lower limbs, enthesitis, and specific organ involvement, most frequently manifesting as anterior uveitis, psoriasis, and IBD. ${ }^{5}$ The clinical symptoms of SpA diseases are characteristically similar and evidence shows that there are genetic similarities; however, there is also heterogeneity among the different SpA diseases. As

*Corresponding author: Di Chen, MD, PhD, Professor and Chairman, Department of Biochemistry, Rush University Medical Center, 1735 West Harrison Street, Cohn Research Building, Suite 508, Chicago, IL 60612-3823. di_chen@ rush.edu.

Conflicts of interest

The authors declare no conflicts of interest 
reported in 1973, the major histocompatibility complex (MHC) class I molecule, human leukocyte antigen (HLA)-B27, is known to be the strongest contributing factor to AS. However, a recent study suggests that other genetic factors, such as endoplasmic reticulum amino-peptidase 1 (ERAP-1) and interleukin (IL)-23R, also play an important role in the pathogenesis of SpA. ${ }^{4}$ Interestingly, polymorphisms of the IL-23R gene (IL23R) have also been identified in psoriasis and IBD. 6,7

The pathological process of SpA can be divided into three stages: ${ }^{8}$ stage 1, inflammation, in which TNF-a is the principal cytokine involved; ${ }^{9}$ stage 2 , erosion; and stage 3 , abnormal bony outgrowth (syndesmorphytes). Syndesmorphytes are the hallmarks of axial SpA. Although the key molecular mechanism is largely unknown and the relationship between inflammation and ankylosis remains controversial, recent findings suggest that Wnt signaling and natural Wnt inhibitors, such as DKK-1 and sclerostin, are involved in stage 3 SpA. Treatment of SpA is primarily based on non-pharmacological and pharmacological treatments, including the use of TNF-a blockers in conjunction with nonsteroidal antiinflammatory agents. Currently, four anti-TNF- $a$ agents are available and approved for the treatment of AS: infliximab, etanercept, adalimumab and golimumab. ${ }^{10}$ However, therapeutic options for patients suffering from the more severe forms of SpA have not been fully developed due to the lack of clear understanding of the cause and progression of the disease. ${ }^{10-12}$ New evidence suggests that treatment with anti-TNF- $\alpha$ agents may relieve pain, but might not alter the progression of radiographic bony proliferation and fusion in patients with AS. ${ }^{13,14}$ Other evidence shows that ankylosis may progress, even with treatment with anti-TNF-a agents. ${ }^{15-17}$ While the mechanism leading to bony outgrowth in SpA needs to be further defined, several studies have demonstrated that the Wnt signaling pathway may contribute to the process of SpA. A further understanding of the relationship between Wnt signaling and new bone formation (syndesmophytes or ankylosis) in SpA could shed light on the therapeutics of these diseases.

\section{Wnt/ß-catenin signaling}

The Wnt family consists of a number of small, cysteine-rich, secreted glycoproteins involved in regulation of a variety of cellular activities with critical roles during development. ${ }^{18-20}$ Wnt proteins trigger signaling pathways within cells that proceed through several protein complexes including $\beta$-catenin. The canonical Wnt signaling pathway regulates $\beta$-catenin expression and its subcellular localization. In the absence of Wnts, $\beta$ catenin levels are kept in steady state. Free $\beta$-catenin proteins are ubiquitinated and degraded by the $26 \mathrm{~S}$ proteasome. ${ }^{21}$ A multiprotein complex containing the kinases GSK-3 $\beta$ and casein kinase-1 (CK1) along with the scaffolding proteins Axis inhibition protein 1 (Axin1), Axin2, adenomatous polyposis coli (APC) and disheveled mediates the degradation of excess $\beta$ catenin. This complex phosphorylates specific amino acid residues on $\beta$-catenin, creating docking sites for the F-box protein/E3 ligase complexes. ${ }^{20,22,23}$ Therefore, inhibition of $\beta$ catenin phosphorylation prevents its degradation and increases its cytoplasmic level and facilitates its nuclear translocation. Signaling from Wnt proteins releases $\beta$-catenin from its binding proteins, allowing it to move to the nucleus, where it interacts with the TCF/LEF transcription factors to activate expression of target genes. ${ }^{19,} 20,24,25$ 
At the cell surface, Wnts interact with two classes of protein: Frizzled receptors and lowdensity-lipoprotein (LDL)-receptor related protein 5 or 6 (LRP5/6). There are many genes encoding frizzled proteins, including 10 in the human genome. Individual frizzled proteins likely have different affinities for various types of Wnt proteins. Wnt proteins can form a complex with both the cysteine-rich domain (CRD) of frizzled and with LRP5/6 simultaneously, leading to the formation of a dual-receptor complex. ${ }^{26,27}$ The intracellular portion of the receptors communicates this binding information and turn on the pathways that act on $\beta$-catenin inside the cell. Following Wnt binding, the intracellular tail of LRP5/6 binds Axin1 (or Axin2) and causes dissociation of $\beta$-catenin from its protein complex, activating $\beta$-catenin signaling. ${ }^{28}$ Sclerostin and DKK1 bind Wnt co-receptors LRP5/6 to inhibit Wnt binding and signaling. Sclerostin and DKK1 bind the first $\beta$-propeller of LRP5 and LRP6 to inhibit Wnt1 class signaling. ${ }^{29,30}$ DKK1 also binds the third $\beta$-propeller to inhibit Wnt3a class signaling. ${ }^{31}$ DKK1 and sclerostin also utilize co-receptors to enhance their inhibitory activity. DKK1 forms a ternary complex with LRP5 or LRP6 and Kremen receptors 1 or 2, which results in internalization of the complex. ${ }^{31,32}$

\section{Wnt signaling in AS}

AS is the major subtype of SpA. ${ }^{12} \mathrm{AS}$ and other forms of SpA are characterized by two major processes: chronic inflammation of the spine and enthesis, and progressive ankyloses. ${ }^{33}$ An enthesis is an anatomical zone in which the fibers of tendons, ligaments, and capsules insert into the bone through a fibrocartilaginous connection. The primary disease location in SpA is hypothesized to be the enthesis. ${ }^{34}$ Excessive bone formation in AS leads to the formation of bone spurs, such as syndesmophytes and enthesiophytes, which contribute significantly to the permanent disability of patients. ${ }^{35}$ The Wnt proteins are critically important in normal bone homeostasis, in particular in osteoblastic new bone formation. Therefore, Wnt proteins may also play a role in the process of new bone formation in AS. ${ }^{36-40}$ Various components of the Wnt signaling molecules were recently found to be involved in maintaining bone mass. The most studied secreted Wnt inhibitors are the dickkopfs (DKKs), sclerostin, and secreted frizzled related proteins, all of which likely play important roles in bone turnover during the disease progression. ${ }^{41}$

\section{DKK1}

DKK is a family of cysteine-rich proteins comprising at least four members: DKK1, DKK2, DKK3 and DKK4. Among these, the one best studied is DKK1, which functions as a natural inhibitor of Wnt signaling. ${ }^{42,43}$ DKK1 was recently recognized as a key player in the process of new bone formation in AS, ${ }^{44-47}$ and DKK1 blockade was shown to lead to the fusion of sacroiliac joints in an animal model of arthritis. ${ }^{45}$ Activation of Wnt signaling by blocking its natural inhibitor DKK1 leads to the formation of osteophytes in peripheral joints. ${ }^{44}$ Heterozygous Dkk1-deficient mice $\left(D k k 1^{+-}\right)$showed increased bone formation and bone mass. ${ }^{46} \mathrm{Dkkl}$ transgenic mice exhibited increased expression of DKK1 and an osteopenic phenotype. ${ }^{47}$ Several recent studies focused on the role of DKK1 in patients with AS; differing results were reported because of the various methodologies utilized in the studies. One study that assessed serum levels of DKK1 using an enzyme-linked immunosorbent assay measuring functional serum DKK1 levels bound to the LRP-6 
receptor showed that DKK1 levels decreased in AS patients, in contrast with patients with rheumatoid arthritis (RA), who exhibited increased DKK1 levels. ${ }^{44}$ Another study reported that patients with AS receiving anti-TNF-a treatment had significantly higher serum DKK1 levels than patients with AS who did not receive anti-TNF-a treatment. Despite increased serum levels, the DKK1 in the sera of AS patients was found to be less able to suppress $\beta$ catenin translocation to the nucleus than that in the control sera, suggesting that the DKK1 in AS patients might not be fully functional. ${ }^{48}$ The German SpA Inception Cohort (GESPIC) study, with a two-year follow-up of AS patients, demonstrated that patients with lower DKK1 levels were more prone to the development of syndesmophytes. ${ }^{49}$ A similar finding from a study conducted in Korea also suggests that DKK1 levels were lower in AS patients than in control subjects. ${ }^{50}$ The high levels of functional DKK1 were associated with protection from radiographically-detected syndesmophyte formation in the GESPIC study. ${ }^{49}$ Although the assay methods used were different in these studies, the findings suggest that DKK1 levels were decreased in AS patients and that these patients had a higher risk of developing syndesmophytes. In addition, although circulating DKK1 levels had increased with anti-TNF-a treatment in AS patients, these increased DKK1 proteins might not have been fully functional.

\section{Sclerostin}

Sclerostin is another Wnt inhibitor that suppresses the Wnt pathway. The levels of sclerostin in osteocytes and in the sera of RA, AS, and osteoarthritis (OA) patients have been investigated; sclerostin levels were found to be significantly lower in AS patients than those in RA and OA patients and healthy controls. ${ }^{51}$ Sclerostin also inhibits bone morphogenetic protein (BMP) signaling. Mechanical loading of osteocytes has been reported to stimulate BMP, ${ }^{52}$ while a decrease of DKK1 and sclerostin levels could activate Wnt and BMP signaling. ${ }^{53}$ These findings may explain why new bone formation selectively involves the entheses, which are subjected to high mechanical loading.

\section{Risk loci}

Certain risk loci linked to the $\mathrm{Wnt} / \mathrm{\beta}$-catenin pathway are related to neo-ossification/ ankylosis in AS patients. ${ }^{54}$ Anthrax toxin-receptor 2 (ANTXR2), a membrane-bound molecule, can interact with LRP6 ${ }^{55}$ and potentially affect new bone formation. LRP6 is an important cell surface receptor in the Wnt/ $\beta$-catenin pathway affecting osteoblast activity. A recent genome-wide association study performed on Han Chinese with $\mathrm{AS}^{56}$ detected two risk loci likely related to bone formation, HAPLN1-EDIL3 at 5q14.3 and ANO6 at 12q12.1. HAPLN1 has been shown to be involved in osteophyte formation ${ }^{57}$ in Japanese women with SpA. EDIL3 has an inhibitory effect on $\mathrm{Wnt} / \beta$-catenin signaling. ${ }^{58}$

\section{Wnt signaling in PsA}

The findings mentioned above point to the possible use of DKK1 and sclerostin as biomarkers for patients with increased risk of development of progressive ankylosis. It has been suggested that DKK1 is a serum-soluble bone turnover biomarker in PsA. ${ }^{59}$ However, findings on DKK1 levels in PsA patients are very different from the findings in AS patients. Levels of DKK1 have been reported to be elevated in patients with PsA compared to healthy 
controls. ${ }^{59,60}$ These findings suggest that, unlike other types of SpA, the new bone formation observed in PsA patients may be regulated by different signaling mechanisms. Therefore, DKK1 may not be useful as a biomarker for PsA. The significance of DKK1 upregulation in patients with PsA needs further investigation.

\section{Wnt signaling in SpA associated with IBD}

Some studies examined the role of Wnt/ $\beta$-catenin pathway in AS related to IBD. ${ }^{61-63}$ Xing et al. ${ }^{61}$ recently created a rat IBD model and found that canonical Wnt signaling was activated in rats with IBD, possibly leading to the suppression of mesenchymal stem cell transplants (MSCTs) differentiating into intestinal epithelium. This research suggests that the canonical Wnt signaling pathway is activated to promote proliferation of intestinal stem cells in IBD. Annalucia et al. ${ }^{62}$ reported that Wnt pathway components could be used as predictive markers for the diagnosis, prevention and treatment of IBD. Carina et al. ${ }^{63}$ found that the drugs used clinically for IBD treatment, such as aminosalicylate mesalazine (5ASA), acted by inhibiting the Wnt/ $\beta$-catenin pathway, indicating that inhibition of the $\mathrm{Wnt} / \beta$-catenin pathway may protect from IBD. Other studies suggest that the Wnt signaling pathway is indirectly associated with IBD; these findings also suggest a role for the Wnt signaling pathway in IBD-associated disease. ${ }^{64-67}$

\section{Cartilage $\beta$-catenin signaling in SpA}

We have recently generated chondrocyte-specific $\beta$-catenin gene (Ctnnbl) conditional activation mice, Ctnnbl(ex3) Col2ER mice, by breeding Ctnnbl(ex3) floxfflox mice with Col2$\mathrm{CreER}^{T 2}$ transgenic mice. ${ }^{68,69}$ Our findings in Ctnnb1(ex3) ${ }^{C o l 2 E R}$ mice include the following. (1) Severe destruction in disc tissues of the spine in 3- and 6-month-old Ctnnbl(ex3) Col2ER mice, including severe loss of cartilage tissue in the growth plate and endplate, disorganized annulus fibrosus (AF) and nucleus pulposus (NP) tissues, and large amounts of osteophyte formation in the disc tissue of the entire spine, was observed. These anomalies were associated with the up-regulation of Mmp13 and Adamts 5 expression in disc tissues of Ctnnbl(ex3) ${ }^{\text {Col2ER }}$ mice. $^{70}$ (2) Deletion of Mmp13 or Adamts5 in Ctnnb1(ex3) ${ }^{C o l 2 E R}$ mice significantly reversed the defects observed in disc tissues of Ctnnbl(ex3) ${ }^{C o l 2 E R}$ mice. ${ }^{71}$ (3) Severe knee joint destruction associated with accelerated maturation of articular chondrocytes was found in 5- and 8-month-old Ctnnbl(ex3) Col2ER mice. ${ }^{72}$ (4) Severe cartilage damage in temporomandibular joint (TMJ) tissues was found in 3- and 6-month-old Ctnnb1(ex3) ${ }^{C o l 2 E R}$ mice; this phenotype was also significantly reversed by deletion of Mmp13 or Adamts5 in the Ctnnb1(ex3) Col2ER background. ${ }^{73}$ (5) Severe damage and loss of proteoglycan at the cartilage surface of the facet joint, demonstrated by Alcian blue and Safranin O staining, were observed in 6- and 9-month-old Ctnnb1(ex3) ${ }^{C o l 2 E R}$ mice. Additionally, constant pain was experienced by 4-9 month-old Ctnnb1(ex3) ${ }^{\text {Col2ER }}$ mice (unpublished data).

As we know, SpA has two major phases, inflammation and bony overgrowth. Spine and joints are the major organs affected in the body during the disease progression. Currently it is unknown if inflammation and bony overgrowth (ankylosis) are linked or separated events. Severe defects in spine, including the degradation of tissues in disc ${ }^{70}$ and in facet joint 
(unpublished data), were observed in cartilage-specific $\beta$-catenin conditional activation mice. In addition to the defects in spine, $\beta$-catenin conditional activation mice also showed OA-like changes in knee join. ${ }^{72}$ These animals also experience severe pain (unpublished data). Based on these observations, we hypothesize that inflammatory cytokine(s) released during the inflammation phase of the disease causes up-regulation of $\beta$-catenin signaling, leading to bony overgrowth during disease progression. The key questions that need to be addressed are: which inflammatory cytokine(s) up-regulates $\beta$-catenin signaling during the disease progression; and what is the molecular mechanism involved in the $\beta$-catenin upregulation process.

It has been reported that IL-1 $\beta$ increased $\beta$-catenin protein levels in rabbit articular chondrocytes. ${ }^{74}$ In addition, it has been shown that TNF- $\alpha$ and IL-1 $\beta$ upregulated $\beta$-catenin signaling in other types of cells. ${ }^{75,76}$ Currently we are actively searching which cytokine(s) up-regulates $\beta$-catenin signaling in chondrocytes during the progression of SpA disease.

\section{Conclusions}

New bone formation is a hallmark of SpA and a major therapeutic challenge. Recent findings suggest that Wnt signaling and the natural Wnt inhibitors DKK1 and sclerostin are likely to play important roles in the process of ankylosis in SpA. Our findings suggest that activation of $\beta$-catenin signaling in cartilage tissue may be the key event leading to spine and joint destruction in patients with SpA. Understanding the molecular mechanisms of the Wnt signaling pathway and new bone formation or ankylosis in SpA could shed light into novel therapeutics for these diseases.

\section{Acknowledgements}

This work has been supported by grants to Di Chen from the National Institute of Health (NIH) (AR 055915 and AR 054465) and the North American Spine Society (NASS).

\section{References}

1. Moll JM, et al. Associations between ankylosing spondylitis, psoriatic arthritis, Reiter's disease, the intestinal arthropathies, and Behcet's syndrome. Medicine (Baltimore). 1974; 53:343-64. [PubMed: 4604133]

2. Dougados M, Baeten D. Spondyloarthritis. Lancet. 2011; 377:2127-2137. [PubMed: 21684383]

3. Garg N, van den Bosch F, Deodhar A. The concept of spondyloarthritis: Where are we now? Best Pract. Res. Clin. Rheumatol. 2014; 28:663-72. [PubMed: 25488776]

4. Braun J, Sieper J. Spondyloarthritiden. Z. Rheumatol. 2010; 69:425-434. [PubMed: 20490514]

5. Burton PR, et al. Association scan of 14,500 nonsynonymous SNPs in four diseases identifies autoimmunity variants. Nat. Genet. 2007; 39:1329-1337. [PubMed: 17952073]

6. Brown MA. Breakthroughs in genetic studies of ankylosing spondylitis. Rheumatology, Oxford. 2008; 47:132-137. [PubMed: 18037607]

7. Cargill M, et al. A large-scale genetic association study confirms IL12B and leads to the identification of IL23R as psoriasis-risk genes. Am. J. Hum. Genet. 2007; 80:273-290. [PubMed: 17236132]

8. Chou CT. How to translate basic knowledge into clinical application of biologic therapy in spondyloarthritis. Clin. Dev. Immunol. 2013; 2013:1-6.

9. Tam LS, Gu J, Yu D. Pathogenesis of ankylosing spondylitis. Nat. Rev. Rheumatol. 2010; 6:399405. [PubMed: 20517295] 
10. Baraliakos X, Braun J. Spondyloarthritides. Best Pract. Res. Clin. Rheumatol. 2011; 25:825-842. [PubMed: 22265264]

11. Ferraccooli G, Gremese E. Should we consider tumor necrosis factor as the only target in spondyloarthritides? J. Rheumatol. Suppl. 2012; 89:94-96. [PubMed: 22751604]

12. Baraliakos X, Braun J. Biologic therapies for spondyloarthritis: what is new? Curr. Rheumatol. Rep. 2012; 14:422-427. [PubMed: 22855297]

13. Lambert RG, et al. Adalimumab significantly reduces both spinal and sacroiliac joint inflammation in patients with ankylosing spondylitis: a multicenter, randomized, double-blind, placebocontrolled study. Arthritis Rheum. 2007; 56:4005-4014. [PubMed: 18050198]

14. Van der Heijde D, et al. Canadian (M03-606) study group; ATLAS study group. Assessment of radiographic progression in the spines of patients with ankylosing spondylitis treated with adalimumab for up to 2 years. Arthritis Res. Ther. 2009; 11:R127. [PubMed: 19703304]

15. Van der Heijde D, et al. Radiographic progression of ankylosing spondylitis after up to two years of treatment with etanercept. Arthritis Rheum. 2008; 58:1324-1331. [PubMed: 18438853]

16. Van der Heijde D, et al. Radiographic findings following two years of infliximab therapy in patients with ankylosing spondylitis. Arthritis Rheum. 2008; 58:3063-3070. [PubMed: 18821688]

17. Van der Heijde D, et al. Adalimumab (HUMIRA®) therapy for Ankylosing spondylitis over 2 years does not demonstrate inhibition of radiographic progression compared with a historical control group. Arthritis Rheum. 2008; 58:S413.

18. Huelsken J, Birchmeier W. New aspects of Wnt signaling pathways in higher vertebrates. Curr. Opin. Genet. Dev. 2001; 11:547-553. [PubMed: 11532397]

19. Moon RT, Bowerman B, Boutros M, Perrimon N. The promise and perils of Wnt signaling through $\beta$-catenin. Science. 2002; 296:1644-1646. [PubMed: 12040179]

20. Westendorf JJ, Kahler RA, Schroeder TM. Wnt signaling in osteoblasts and bone diseases. Gene. 2004; 341:19-39. [PubMed: 15474285]

21. Aberle H, Bauer A, Stappert J, Kispert A, Kemler R. $\beta$-catenin is a target for the ubiquitinproteasome pathway. EMBO J. 1997; 16:3797-3804. [PubMed: 9233789]

22. Behrens J, Jerchow BA, Wurtele M, Grimm J, Asbrand C, Wirtz R, Kuhl M, Wedlich D, Birchmeier W. Functional interaction of an axin homolog, conductin, with beta-catenin, APC, and GSK3beta. Science. 1998; 280:596-599. [PubMed: 9554852]

23. Jiang J, Struhl G. Regulation of the Hedgehog and Wingless signalling pathways by the F-box/ WD40-repeat protein Slimb. Nature. 1998; 391:493-6. [PubMed: 9461217]

24. Staal FJ, Clevers H. Tcf/Lef transcription factors during T-cell development: unique and overlapping functions. Hematol. J. 2000; 1:3-6. [PubMed: 11920163]

25. Cliffe A, Hamada F, Bienz M. A role of Dishevelled in relocating Axin to the plasma membrane during wingless signaling. Curr. Biol. 2003; 13:960-966. [PubMed: 12781135]

26. Bejsovec A. Wnt signaling: an embarrassment of receptors. Curr Biol. 2000; 10:R919-22. [PubMed: 11137030]

27. Huelsken J, Vogel R, Erdmann B, Cotsarelis G, Birchmeier W. $\beta$-catenin controls hair follicle morphogenesis and stem cell differentiation in the skin. Cell. 2001; 105:533-45. [PubMed: 11371349]

28. Mao J, Wang J, Liu B, Pan W, Farr GH 3rd, Flynn C, Yuan H, Takada S, Kimelman D, Li L, Wu D. Low-density lipoprotein receptor-related protein-5 binds to Axin and regulates the canonical Wnt signaling pathway. Mol. Cell. 2001; 7:801-9. [PubMed: 11336703]

29. Ettenberg SA, Charlat O, Daley MP, Liu S, Vincent KJ, Stuart DD, Schuller AG, Yuan J, Ospina B, Green J, Yu Q, Walsh R, Li S, Schmitz R, Heine H, Bilic S, Ostrom L, Mosher R, Hartlepp KF, Zhu Z, Fawell S, Yao YM, Stover D, Finan PM, Porter JA, Sellers WR, Klagge IM, Cong F. Inhibition of tumorigenesis driven by different Wnt proteins requires blockade of distinct ligandbinding regions by LRP6 antibodies. Proc. Natl. Acad. Sci. USA. 2010; 107:15473-15478. [PubMed: 20713706]

30. Bourhis E, Tam C, Franke Y, Bazan JF, Ernst J, Hwang J, Costa M, Cochran AG, Hannoush RN. Reconstitution of a frizzled8.Wnt3a.LRP6 signaling complex reveals multiple Wnt and Dkk1 binding sites on LRP6. J. Biol. Chem. 2010; 285:9172-9179. [PubMed: 20093360] 
31. Ke HZ, Richards WG, Li X, Ominsky MS. Sclerostin and Dickkopf-1 as therapeutic targets in bone diseases. Endocr Rev. 2012; 33:747-783. [PubMed: 22723594]

32. Ellwanger K, Saito H, Clement-Lacroix P, Maltry N, Niedermeyer J, Lee WK, Baron R, Rawadi G, Westphal H, Niehrs C. Targeted disruption of the Wnt regulator Kremen induces limb defects and high bone density. Mol. Cell. Biol. 2008; 28:4875-4882. [PubMed: 18505822]

33. Schett G. Bone formation versus bone resorption in ankylosing spondylitis. Adv. Exp. Med. Biol. 2009; 649:114-121. [PubMed: 19731624]

34. McGonagle D, Gibbon W, Emery P. Classification of inflammatory arthritis by enthesitis. Lancet. 1998; 352:1137-1140. [PubMed: 9798608]

35. Van Echteld I, et al. Identification of the most common problems by patients with ankylosing spondylitis using the international classification of functioning, disability and health. J. Rheumatol. 2006; 33:2475-2483. [PubMed: 17013999]

36. Goldring SR, Goldring MB. Eating bone or adding it: the Wnt pathway decides. Nat. Med. 2007; 13:133-134. [PubMed: 17290270]

37. Baron R, Rawadi G. Targeting the Wnt/beta-catenin pathway to regulate bone formation in the adult skeleton. Endocrinology. 2007; 148:2635-2643. [PubMed: 17395698]

38. Johnson ML, Kamel MA. The Wnt signaling pathway and bone metabolism. Curr. Opin. Rheumatol. 2007; 19:376-382. [PubMed: 17551370]

39. Krishnan V, Bryant HU, Macdougald OA. Regulation of bone mass by Wnt signaling. J. Clin. Invest. 2006; 116:1202. [PubMed: 16670761]

40. Bodine PV, Komm BS. Wnt signaling and osteoblastogenesis. Rev. Endocr. Metab. Disord. 2006; 7:33-39. [PubMed: 16960757]

41. Schett G, Zwerina J, David JP. The role of Wnt proteins in arthritis. Nat. Clin. Pract. Rheumatol. 2008; 4:473-480. [PubMed: 18756273]

42. Glinka A, et al. Dickkopf-1 is a member of a new family of secreted proteins and functions in head induction. Nature. 1998; 391:357-362. [PubMed: 9450748]

43. Bafico A, et al. Novel mechanism of Wnt signalling inhibition mediated by Dickkopf-1 interaction with LRP6 /Arrow. Nat. Cell Biol. 2001; 3:683-686. [PubMed: 11433302]

44. Diarra D, et al. Dickkopf-1 is a master regulator of joint remodeling. Nat. Med. 2007; 13:156-163. [PubMed: 17237793]

45. Uderhardt $S$, et al. Blockade of Dickkopf ( DKK)-1 induces fusion of sacroiliac joints. Ann. Rheum. Dis. 2010; 3:592-597. [PubMed: 19304568]

46. Morvan F, et al. Deletion of a single allele of the Dkk1 gene leads to an increase in bone formation and bone mass. J. Bone Miner. Res. 2006; 21:934-945. [PubMed: 16753024]

47. Baron R, Rawadi G. Minireview: Targeting the Wnt/B-Catenin pathway to regulate bone formation in the adult skeleton. Endocrinology. 2007; 148:2635-2643. [PubMed: 17395698]

48. Daoussis D, et al. Evidence that Dkk-1 is dysfunctional in ankylosing spondylitis. Arthritis Rheum. 2010; 62:150-158. [PubMed: 20039407]

49. Heiland GR, et al. High level of functional dickkopf-1 predicts protection from syndesmophyte formation in patientswith ankylosing spondylitis. Ann. Rheum. Dis. 2012; 71:572-574. [PubMed: 22186710]

50. Kwon SR, et al. Dickkopf-1 level is lower in patients with ankylosing spondylitis than in healthy people and is not influenced by anti-tumor necrosis factor therapy. Rheumatol. Int. 2012; 32:25232527. [PubMed: 21833531]

51. Appel H, et al. Altered skeletal expression of sclerostin and its link to radiographic progression in ankylosing spondylitis. Arthritis Rheum. 2009; 60:3257-3262. [PubMed: 19877044]

52. Santos A, et al. Mechanical loading stimulates BMP7, but not BMP2, production by osteocytes. Calcif. Tissue Int. 2011; 89:318-326. [PubMed: 21842277]

53. Bonewald LF, Johnson ML. Osteocytes, mechanosensing and Wnt signaling. Bone. 2008; 42:606615. [PubMed: 18280232]

54. Tsui FW, et al. The genetic basis of ankylosing spondylitis: new insights into disease pathogenesis. Appl. Clin. Genet. 2014; 7:105-115. [PubMed: 24971029] 
55. Deuquet J, et al. The dark sides of capillary morphogenesis gene 2. EMBO J. 2012; 31:3-13. [PubMed: 22215446]

56. Lin Z, et al. A genome-wide association study in Han Chinese identifies new susceptibility loci for ankylosing spondylitis. Nat. Genet. 2011; 44:73-77. [PubMed: 22138694]

57. Urano T, et al. Single-nucleotide polymorphism in the hyaluronan and proteoglycan link protein 1 (HAPLN1) gene is associated with spinal osteophyte formation and disc degeneration in Japanese women. Eur. Spine J. 2011; 20:572-577. [PubMed: 20953637]

58. Takai A, et al. Anterior neural development requires Del1, a matrix-associated protein that attenuates canonical Wnt signaling via the Ror2 pathway. Development. 2010; 137:3293-3302. [PubMed: 20823067]

59. Jadon DR, et al. Serum Soluble Bone Turnover Biomarkers in Psoriatic Arthritis and Psoriatic Spondyloarthropathy. J. Rheumatol. 2014; 42:21-30. [PubMed: 25362660]

60. Dalbeth $\mathrm{N}$, et al. Circulating mediators of bone remodeling in psoriatic arthritis: implications for disordered osteoclastogenesis and bone erosion. Arthritis Res Ther. 2010; 12:R164. [PubMed: 20796300]

61. Xing YF, et al. Expression of Wnt and Notch signaling pathways in inflammatory bowel disease treated with mesenchymal stem cell transplantation: evaluation in a rat model. Stem Cell Res. Ther. 2015; 6:101. [PubMed: 25998108]

62. Serafino A, et al. Wnt-pathway components as predictive markers useful for diagnosis, prevention and therapy in inflammatory bowel disease and sporadic colorectal cancer. Oncotarget. 2014; 5:978-992. [PubMed: 24657851]

63. Bos CL, et al. Protein phosphatase $2 \mathrm{~A}$ is required for mesalazine-dependent inhibition of Wnt/betacatenin pathway activity. Carcinogenesis. 2006; 27:2371-2382. [PubMed: 16728434]

64. Hughes KR, Sablitzky F, Mahida YR. Expression Profiling of Wnt Family of Genes in Normal and Inflammatory Bowel Disease Primary Human Intestinal Myofibroblasts and Normal Human Colonic Crypt Epithelial Cells. Inflamm. Bowel Dis. 2011; 17:213-220. [PubMed: 20848536]

65. Marian MH, et al. WNT-pathway activation in IBD-associated colorectal carcinogenesis: Potential biomarkers for colonic surveillance. Cell. Oncol. 2010; 32:303-310. [PubMed: 20208143]

66. Dhir M, et al. Epigenetic Regulation of WNT Signaling Pathway Genes in Inflammatory Bowel Disease (IBD) Associated Neoplasia. J. Gastrointest. Surg. 2008; 12:1745-1753. [PubMed: 18716850]

67. You XJ, et al. Expression of Wnt pathway components frizzled and disheveled in colon cancer arising in patients with inflammatory bowel disease. Oncol. Rep. 2007; 18:691-694. [PubMed: 17671721]

68. Chen M, et al. Generation of a Transgenic Mouse Model With Chondrocyte-Specific and Tamoxifen-Inducible Expression of Cre Recombinase. Genesis. 2007; 45:44-50. [PubMed: 17211877]

69. Zhu M, et al. Tamoxifen-inducible Cre-recombination in articular chondrocytes of adult Col2a1CreERT2 transgenic mice. Osteoarthr. Cartilage. 2008; 16:129-130.

70. Wang $\mathrm{M}$, et al. Conditional activation of $\beta$-catenin signaling leads to severe defects in intervertebral disc tissue. Arthritis Rheum. 2012; 64:2611-2623. [PubMed: 22422036]

71. Wang M, et al. MMP13 is a critical target gene during the progression of osteoarthritis. Arthritis Res. Ther. 2013; 15:R5. [PubMed: 23298463]

72. Zhu M, et al. Activation of $\beta$-catenin signaling in articular chondrocytes leads to osteoarthritis-like phenotype in adult beta-catenin conditional activation mice. J. Bone Miner. Res. 2009; 24:12-21. [PubMed: 18767925]

73. Wang M, et al. Activation of $\beta$-catenin signalling leads to temporomandibular joint defects. Eur. Cells Mater. 2014; 28:223-235.

74. Ryu JH, Kim SJ, Kim SH, Oh CD, Hwang SG, Chun CH, Oh SH, Seong JK, Huh TL, Chun JS. Regulation of the chondrocyte phenotype by beta-catenin. Development. 2002; 129:5541-50. [PubMed: 12403723]

75. Johnson A. TNF-induced activation of pulmonary microvessel endothelial cells: a role for GSK3beta. Am J Physiol Lung Cell Mol Physiol. 2009; 296:L700-9. [PubMed: 19218353] 
76. Kaler P, Augenlicht L, Klampfer L. Macrophage-derived IL-1 $\beta$ stimulates Wnt signaling and growth of colon cancer cells: a crosstalk interrupted by vitamin D3. Oncogene. 2009; 28:3892902. [PubMed: 19701245] 